Law

\section{The role of the expert witness}

\section{Williams}

\section{Medical practitioners must remain objective}

$\mathrm{T}$ he ideal expert witness is a person with special training, knowledge, or experience whose role is to aid the court. Re X (Non-Accidental Injury: Expert Evidence) $)^{1}$ is the latest in a series of cases $^{23}$ in which the evidence of an expert witness has been criticised by a judge in a case involving alleged child abuse. The case is important not just because the same individual, Dr Colin Paterson, has been censured, thus calling into question his status as an expert witness in both civil and criminal cases, but also because there are more general lessons to be learned both from the criticisms aimed at the expert and from other more general issues arising from the case.

In $R e X$ the local authority were seeking a care order on a child who had been admitted to hospital, aged 20 weeks, with a number of fractures. Both parents of the child denied causing any harm to her but neither of them suggested that she could have come to harm at the hands of a third party. The local authority's case was that the child must have come by those fractures nonaccidentally and that one of the parents was responsible. The parents instructed Dr Paterson, who put forward an alternative explanation for the injuries. He said the fractures had probably been caused by temporary brittle bone disease (TBBD).

In rejecting Dr Paterson's evidence, Singer J pointed out a number of flaws in his evidence and concluded that Dr Paterson had fallen into the same trap as he had in the previous cases in which he was criticised. As a consequence, Singer $\mathrm{J}$ concluded that in future, before Dr Paterson is given leave to report in any case, his methodology and his credentials to express an opinion should be subjected to rigorous scrutiny by a High Court judge.

The duties of an expert in a case involving child abuse were laid out by Cazalet $\mathrm{J}$ in Re $J$ (Child Abuse: Experts Evidence $)^{45}$ in which he stated three fundamental requirements of an expert witness. He said:

"If experts look for and report on factors which tend to support a particular proposition or case, their reports should still: (a) provide a straightforward, not a misleading opinion; (b) be objective and not omit factors which do not support their opinion; and (c) be properly researched."

When dismissing Dr Paterson's evidence in $R e X$ the court concluded that he breached all three of these requirements. Singer J commented:

"Dr Paterson has in my opinion provided a misleading opinion, failed to be objective, omitted factors which do not support his opinion, and lacked proper research in his approach to the case in point. Thus he fails all Cazalet J's tests."

\section{ISSUES OF RELEVANCE TO EXPERT WITNESSES ARISING FROM THIS CASE}

\section{Agreement between expert}

witnesses

The courts in child abuse proceedings have increasingly encouraged experts to attempt to reach agreement on as many issues as possible. Indeed, experts are invited to confer with each other before the final hearing both in order to exchange information that may assist them in forming their opinions, and to attempt to reach agreement or limit the issues. ${ }^{6}$ In $\operatorname{Re} X$ Singer $\mathrm{J}$ was at pains to point out that, due to the seriousness of their nature, care proceedings must impose extremely high standards on all those involved with them and this must be reflected in the court process. Thus the court should ensure that all relevant expert advice and potential difference of opinion should be put before it. In this particular case, however, the introduction of Dr Paterson's evidence led to a 4 month delay in reaching a judgment, and this delay was due to the controversial nature of the diagnosis he proffered. Delay has a large cost, not just for the child, but the parents too.

\section{Lapses in expert evidence}

Singer J highlighted a number of lapses made by Dr Paterson in giving his evidence. The first of these related to bruising on the child. As part of his theory of TBBD, Dr Paterson proposes that bruising at the site of a fracture is often absent. Thus, insofar as the bruise that was observed was apparently a contra-indication of TBBD, he should have explained what weight, if any, he gave that bruise in the formulation of his opinion. Instead, he treated it as a matter of no significance, in contrast to all the other medical opinion, where the view was expressed that any bruise upon the body of an immobile child incapable of self-injury is of great significance. Similarly, in relation to swelling of the child's leg, he said that he did not discuss this as it is "generally accepted in medicine that swelling is a normal consequence of fracture which just happens". He therefore assumed this would not be a contentious area. However, not only was this assumption unwarranted according to the other expert evidence, butaccording to his theory-swelling, if caused by external trauma, would counter-indicate TBBD. Thus Singer J concluded that "by failing to deal in his report with the bruising and swelling, he misled by omission to a very serious extent".

Singer $J$ also found that whilst $\mathrm{Dr}$ Paterson did state that his work in this area "remains controversial", he nonetheless went on to assert, with misplaced increasing confidence, that TBBD is a real disorder. This, singer J found, plainly showed a continuing lack of objectivity. Dr Paterson failed to refer to and discuss factors which did not support his opinion and thus appeared to have a preconception as to the outcome. Singer J commented:

"[TBBD] is, in my opinion, a syndrome which can only be recognised by someone with tunnel vision who notes only those positive factors which are selfselected, and adapts his description of the disease as he goes along, thus enabling him to disregard, indeed to ignore, factors which from his own published work one would suppose he might regard as relevant."

\section{Who is an expert?}

Experts are recognised as such by the courts either because they have relevant professional qualifications or because of relevant practical experience, or because they have a combination of the two features. In cases of child abuse the court is particularly likely to prefer that the expert has sufficient practical experience in the area, rather than simply being qualified in a particular discipline. ${ }^{7}$ When the expert gives evidence the court does not expect the "right answer" on difficult and contentious issues, rather the expectation is that the expert will give an informed opinion from which the court can draw its own conclusions.

Dr Paterson does not present himself as an expert in radiology, paediatrics, or generally in relation to child abuse issues. Where Dr Paterson has arguably gone wrong is in developing a so-called expertise in one particular area. This expertise stems from his undoubted expertise in the field of osteogenesis imperfecta and osteoporosis, in which 
areas he has a good record of high quality research. The court in Re X acknowledged the important contribution Dr Paterson had made at an earlier stage of his career in a number of cases by establishing OI, rather than abuse, as the cause of a fracture in some children. However, his knowledge of child abuse in general is extremely limited. The children he sees are medico-legal cases referred to him seeking his view upon the potential for an alternative diagnosis to abuse as the cause of fractures. Thus he sees only a very limited cohort of children, rather than a broad spectrum of the population, as would a paediatrician.

\section{How can an expert witness avoid controversy?}

For those medical experts engaged in innovative research the question must arise at what point can any new theory propounded by them be presented to the court. It is necessarily difficult to answer that question in a vacuum. However, the problem for the court in handling new theories was well illustrated by Judge Cohen in one of the reported cases arising out of the Cleveland crisis. ${ }^{8}$ In Cleveland County Council $v D^{9}$, talking about the anal dilatation test, Judge Cohen commented:

"The technique is controversial. It has only...'been on the scene' for about a year and it is a fairly new theory...They may well be proved right . . .Time will only tell...because the theory is new and because it is controversial ... it is necessary to look at the evidence with extreme care, and examine in detail not only the oral evidence but all the relevant documentation in each case; and therein lies the difficulty here because there is no, or no adequate documentation to which I can turn."

However, by considering some of the criticisms directed at Dr Paterson this does give the expert some pointers of which to be aware. The first of these is that in developing his theory about TBBD, as Cazalet J commented, "I think he may have developed a theory of causation rather than a diagnosis". The point Cazalet J was making here was that he felt that Dr Paterson had assembled what he considered to be a number of common features in cases of children with broken bones. He had then gone on to theorise that if these features were present in a case where a child presented with broken bones then the cause of the injury was TBBD. Thus he did not attempt to analyse what had occurred but simply ascribed his theory.

Another important point made by the court is the weight of other medical opinion. Dr Paterson had given evidence as to his publication record on TBBD. However, the court found that of an article published in 1993, it was in a relatively obscure publication and may well not have been peer reviewed by appropriate experts. Furthermore, since Dr Paterson first promulgated his theory "tens of thousands of researchers will have been looking for supporting evidence". If such evidence were to be found it would by now have been published. In direct contrast to Dr Paterson's work, in the April 2000 issue of Pediatrics ${ }^{10}$ an article appeared describing the "largest report of rib fractures in infants to date". Singer J held: "Its conclusion is that most rib fractures in infants are caused by child abuse. Its detailed observations and conclusions run starkly counter to themes in the evidence of Dr Paterson."

\section{CONCLUSION}

When giving expert evidence in cases of child abuse medical practitioners should always bear in mind the duties imposed on them. The fundamental position is that the expert owes his duty not to the party who instructs him, but to the court. ${ }^{11}$ An expert must not assume the role of an advocate. This means that the expert must be objective at all times. It follows from this that the expert should never ignore relevant factual evidence, or omit to consider other relevant material, even if that evidence tends to throw some doubt on the expert's conclusion. The expert must ensure that his evidence is properly researched, drawing upon the published literature. He must also ensure that his own research is methodologically sound. In particular, an expert who is involved in new research should be conscious of the natural tendency to promote his own findings and should make every attempt to avoid becoming subjectively biased. If the expert conforms with these duties then the requirement to provide objective, unbiased assistance to the court should not present the expert with any difficulties.

Arch Dis Child 2002;87:267-268

Author's affiliation

C Williams, Department of Law, The University of Sheffield, Crookesmoor Building, Conduit Road, Sheffield S10 IFL, UK;

c.williams@sheffield.ac.uk

\section{REFERENCES}

$1 \operatorname{Re} X$ (Non-accidental Injury: Expert Evidence) 2001:2 FLR 90.

2 Re J (Child Abuse: Experts' Evidence) 1991:FCR 192. Also reported as $\operatorname{Re} R(A$ Minor)(Expert Evidence) 1991:1 FLR 291.

3 Re AB (Child Abuse: Expert Witnesses) 1995: 1 FLR 181.

4 Re J (Child Abuse: Experts' Evidence) 1991:FCR 192.

5 Williams C. Expert evidence in cases of child abuse. Arch Dis Child 1993;68:712-14.

$6 \operatorname{Re} C$ (Expert Evidence: Disclosure: Practice) 1995: 1 FLR 204.

7 See e.g. Rochdale Borough Council v A and Others 1991: 2 FLR 192.

8 Butler-Sloss E. Report of the Inquiry into Child Abuse in Cleveland 1987. Cm 412, 1988 HMSO.

9 1998:FCR 615.

10 Bulloch B, Schubert CJ, Brophy PD, et al. Cause and clinical characteristics of rib fractures in infants. Pediatrics 2000; 105:e48.

11 Vernon v Bosely (Expert Evidence) 1998:1 FLR 